\title{
Using Swimming Speed as an Indicator of Malformation: A Practical Approach for Identification and Removal of Juvenile Seabass (Dicentrarchus labrax L., 1758) with Skeletal Deformity
}

\author{
Ali Yıldırım Korkut ${ }^{1, a, *}$, Tolga Mustafa Tolon ${ }^{1, b}$, Kutsal Gamsız ${ }^{1, c}$, Aysun Kop $^{1, d}$ \\ ${ }^{1}$ Department of Aquaculture, Ege University, Fisheries Faculty, 35100 Bornova/İzmir, Turkey
}

*Corresponding author

\section{A R T I C L E IN F O A B S T R A C T}

Research Article

Skeletal abnormalities in farmed fish are one of the main problems that negatively affect the production enterprises in terms of economic, biological and animal health. Fish with skeletal deformities in hatcheries are considered as non-economic individuals and are therefore detected and removed manually from the production tanks, which is a time consuming and laborious work for

Received : 10/03/2021

Accepted : 10/04/2021 the facilities. Since the formation of abnormalities in the skeletal structure of the fish during the early growth period cause reduced swimming ability or speed that prevent fish to compete during feeding. Further, since deformed fish has no market value, even the share of a small amount of feed among deformed fish will reduce the feed conversion for the market targeted individuals within the culture tank that in terms may increase the production cost per fish. Therefore, in culture conditions it is important to remove the deformed fish from the tank environment by quickly determining those fellows at the early stage of growth. The present study evaluates the effects of water velocity on swimming behavior of juvenile seabass (Dicentrarchus labrax) and provides a solution for a rapid identification -and mechanical removal of deformed fish from the culture environment by using swimming speed slowdown -and behavioral differences as an indicator of deformation.

Keywords:

Aquaculture

Seabass

Dicentrarchus labrax

Skeletal deformity

Swimming speed https://orcid.org/0000-0002-1096-5725 https://orcid.org/0000-0003-3277-9488 b@tolga.tolon@ege.edu.tr aysun.kop@ege.edu.tr https://orcid.org/0000-0002-2233-0663 https://orcid.org/0000-0003-1724-5672

\section{Introduction}

Developments and significant increases in aquaculture in recent years necessitate the implementation of intensive aquaculture systems. In aquaculture facilities, the effects of many factors such as nutrition and feeding, diagnosis and treatment of diseases, marketing and distribution and several applications of maintenance that affect the production cost in aquaculture facilities are directly linked to the success of production. Skeletal deformations in the early stage of juveniles are considered among major problems affecting operational and production success in marine fish hatcheries. A consistent number of skeletal anomalies have been reported in the hemal and caudal body regions of seabass (D. labrax) from different Mediterranean hatcheries (Afonso et al, 2000). It has also been reported by various researchers that the production of seabass and seabream (Sparus aurata L.) is severely damaged by the frequency of skeletal deformation
(Balebona et al., 1993; Chatain, 1994; Boglione et al., 2013).

Fish with malformation is disadvantageous in the marketing due to their shape and appearance, different than the normal fish condition. Therefore, deformed fish may either receive less value compared to the normally grown fish or even no demand at all. Spinal deformity in reared fish affects the external morphology, growth and survival of fish negatively and the decrease in the quality of the fish constitutes the main reason of economic loss (Andrades et al., 1996; Afonso et al, 2000; Kihara et al, 2002). Deformed fish with low economic value results in economic losses in the enterprises in terms of both feed consumption and negative contributions to the stock density in the tank. Regular detection of these fishes and their removal from production areas require additional labor and time. 
Although many studies have been conducted to identify and prevent the factors that cause deformations, there is no clear evidence for the reason of skeletal deformations in the hatcheries. Skeletal systems of reared fish generally show normal development under suitable conditions (Kihara et al., 2002; Powell et al., 2009). However, deficiencies of various vitamins such as vitamin $\mathrm{C}$ and vitamin $\mathrm{A}$, other nutritional deficiencies of calcium and phosphorus, water conditions and dynamics, genetic factors, defects in the formation of air sacs, various bacterial and parasitic diseases (Berillis, 2015), or even a combination of all these factors can be linked to the reasons of malformation in the skeletal structure of fish.

Skeletal system deformations such as lordosis, scoliosis and brachyospondylie, which are frequently seen in hatchery fry fish, show reduced growth performance and increased mortality (Kihara et al., 2002). Due to the swelling of the swimming sac (Chatain and Dewavrin, 1989), intense water in pre-hemal vertebrae or in larval breeding tanks, Lordosis may develop in the hemal spine as a result of flow velocity (Divanach et al., 1997; Kihara et al., 2002). Lordosis is one of the most serious deformations observed in aquaculture facilities and the degree of hemal lordosis ranges from mild axial modification to acute lordosis angles (Divanach et al., 1997; Korkut et al., 2009) and therefore, the study of the effects of deformation on body shape is of primary importance for standardizing a scale for precise quality assessment in hatcheries.

The general morphological structure of a fish is called width -and cord length, respectively, whose fin measurement is normal and parallel to water flow. Swimming occurs when momentum passes from the fish to the surrounding body of water, or from the body of water to the fish. Fundamental momentum mechanisms are listed as drag, remove, speed up (Videler, 1993).

For swimming fish, the hydrodynamic lift created in addition to buoyancy and vertical pressure force should ensure buoyancy. Many fish achieve this by constantly swimming with their pectoral fins. However, when induced drag occurs as a side effect of this technique, the balance between horizontal pressure forces is disturbed and the fish must make corrections to balance the constant swimming speed. According to hydrodynamic stability and the directions of motion are often described as roll, pitch and yaw. The swimming patterns used by the fish determine the shape of the propulsive forces and the size of the force components. Although there are studies on the relationship between stable lift and pull forces there are relatively few studies on the relationship between shape and acceleration reaction (O'Steen and Bennett, 2003),

In this study, it is aimed to create a design that allows fish with skeletal deformations to be detected and quickly removed from the environment without disturbing normal fish in tank with no malformation by using swimming speed as an indicator. The designed model provides a mechanical method focused on the separation and removal of deformed juveniles from culture environment by using increased current velocity in tanks that is suitable for the use in all fish farming facilities and can make a significant contribution to the success and best management efforts of hatcheries.

\section{Material and Method}

\section{Experimental Fish}

In the experiment, 150 seabass (D. labrax) juveniles with an average body weight of $2 \pm 0.08 \mathrm{~g}$ was obtained from a commercial marine hatchery (Akvatek Aquaculture Inc., Turkey).

\section{Experimental Flow-Tank System}

The experiment was carried out in the aquaculture laboratories (Urla Campus) and the Fish Nutrition and Feed Technology Laboratory (Bornova Campus) of the Faculty of Fisheries at the Ege University, Izmir-Turkey.

The tank model specially designed for this study was manufactured by AKYA Marine and Fisheries Equipment Co., Turkey. The system used in the experiment, which creates water flow velocity and allows the water to rotate, is made of PVC material and is approximately $2 \mathrm{~m}$ in length and $55 \mathrm{~cm}$ in width. The experimental system and setup are shown in Figure 1. In the system, a digital speedadjustable water pump of $0.35 \mathrm{Kw}$ PE body (2) allows water rotation. Each of the parts and elements of the flowtank system developed for separating deformed fish from normally formed individuals have been numbered and are given in Figure 1.
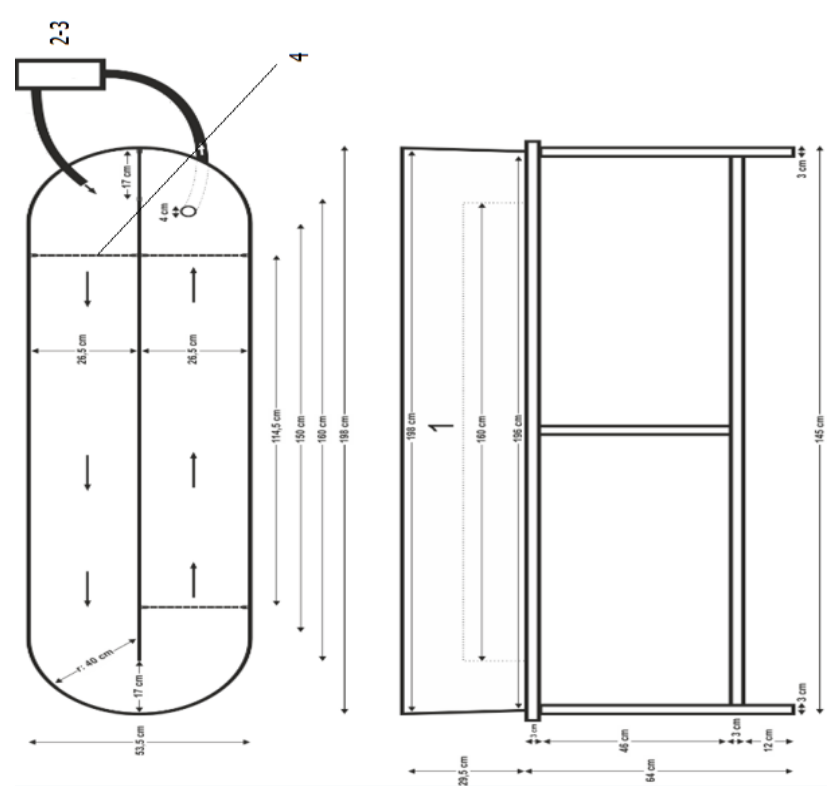

Figure 1. General Scheme of the Experimental Flow-tank Sistem (1 Water flow-tank, 2 Water pump, 3 Pump speed control interface 4 Intermediate covers).

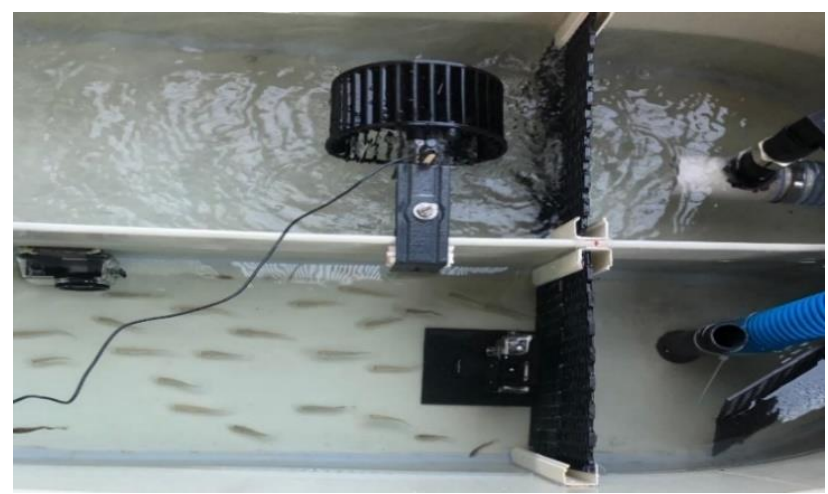

Figure 2. General View of the Experimental Flow-Tank. 


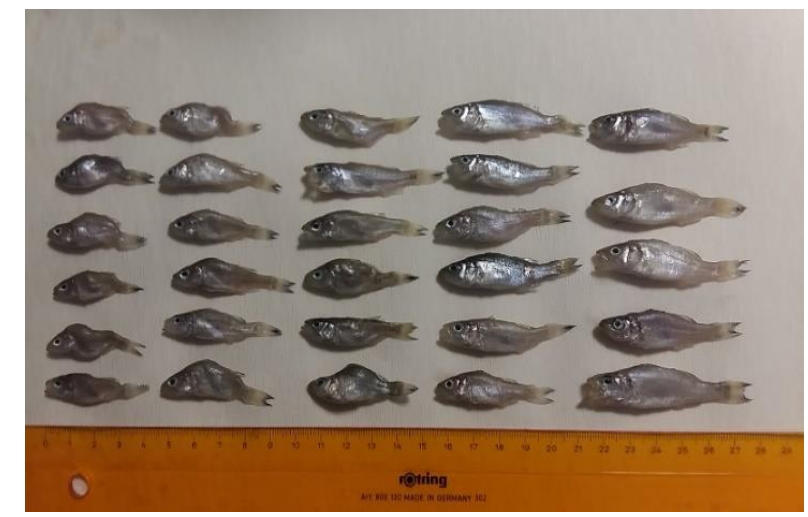

Figure 3. General View of the Fish Used in the Experiment

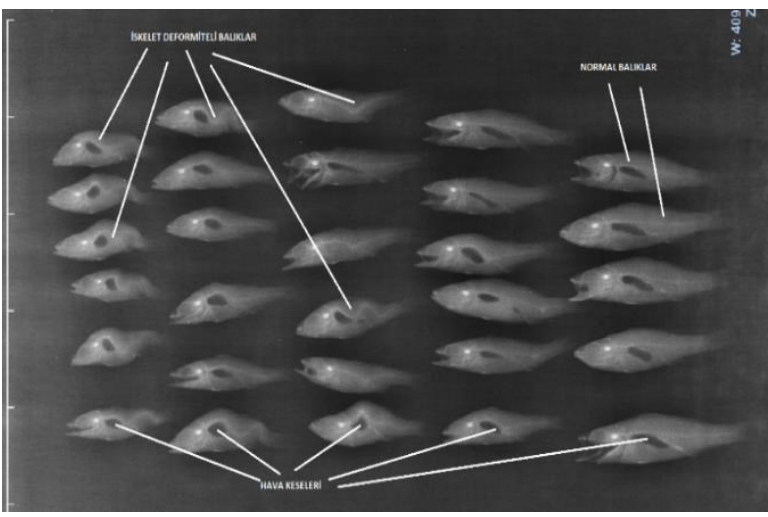

Figure 4. X-Ray Images of Trial Fish

Table 1. Observation of Water Inlet and Flow Speed in the Experimental Flow-tank $(\mathrm{m} / \mathrm{sec})$.

\begin{tabular}{cc|ccc}
\hline \multicolumn{2}{c|}{ Flow Speed (m/sec) } & \multicolumn{3}{c}{ Observation } \\
\hline Pomp Water Inlet & Swimming Area (in tank) & Normal Fish & Deformed Fish & Time (sec) \\
\hline 2,5 & 0.2 & Swimming is normal & Swimming is normal & \\
3.0 & 0.3 & Swimming is normal & Group swimming & 20 \\
3.3 & 0.35 & Swimming is normal & Group swimming & 40 \\
3,5 & 0.4 & Swimming is normal & Group swimming & 60 \\
3.8 & 0.5 & Swimming is normal & Slowing down & 75 \\
4.0 & 0.6 & Swimming is normal & Separation from the group & 96 \\
4.5 & 0.8 & Swimming is normal & Fatigue and slowdown & 123 \\
5,0 & 0.9 & Swimming is normal & Stopping and separation & 158 \\
\hline
\end{tabular}

Within the recirculated system, water flow is generated by using a circulation pump set to the fish containment. The pump speed control interface (Optidrive E3, ode-3120043-1f12-01, 0.5 HP) (3) is the part where the flow speed can be controlled, which can increase or decrease level of water speed in the flow-tank.

Three different speedometers were used for water velocity measurements. For water flow rate calibration, control was provided with a different flow rate meter than the test system, to enable a comparative evaluation of the test results. In the study, a total of 4 camera systems of Gopro Hero 4 and 5 models were used for surface and underwater imaging. All image recordings were evaluated afterwards. The general view of the experimental flowtank is given in Figure 2.

An X-ray imaging system was used for the definitive diagnosis of fish with skeletal deformation. For this purpose, General Electric KV 65 MAS 125 X-Ray device was used in EGERAD Radiology and Nuclear Medicine Laboratory.

\section{Implementation of the Trial}

The trial was repeated five times and each time 30 individuals of randomly selected seabass juveniles out of a batch of normal and deformed fish stock were tested in the experimental flow-tank. Once a trial was set, visual monitoring and camera recording was continued for a period of 60 seconds for each unit speed treatment. During this process, the swimming speeds of the fish were recorded and the highest swimming speeds at which the deformed fish could withstand were noted. Since deformations in fish are considered as general skeletal deformation and there will be deformation differences between fish (lordosis angles, scoliosis or lordosis may be), therefore statistical comparison has not been made.

\section{Results}

Randomly selected fish obtained from the commercial marine hatchery were tested in the experimental flow-tank designed and manufactured for this study. During the trial, fish were studied under conditions (salinity, temperature) suitable for the water conditions in the production place. Normal and X-Ray views of the fish used in the experiment are given in Figures 3 and 4.

Since the aim of the study was to separate fish with skeletal deformities from the individuals with normal appearance, it was planned to use the flow velocity of the water. The results obtained with a total of five applications were compiled. Since the values obtained in the study differ in flow rate of the water entered the tank and the water flow rate in the tank, water flow rates were measured separately from these two parts. Thus, real results in the tank were obtained. Accordingly, the findings and evaluations obtained according to the flow velocities at the end of the study are given in Table 1.

The trial was repeated five times and each time 30 individuals of randomly selected seabass juveniles out of a batch of normal and deformed fish stock were tested in the experimental flow-tank. According to the results of the study, it was observed that the deformed fish decelerated from the $75^{\text {th }}$ second at a speed of $0.5 \mathrm{~m} / \mathrm{sec}$, and the separation from the group was observed at $96^{\text {th }}$ second when water flow increased to $0.6 \mathrm{~m} / \mathrm{sec}$. Deformed fish remained behind the group at a velocity speed of $0.8 \mathrm{~m} / \mathrm{sec}$. It has been observed that normal fish continued schooling behavior following each other within the group, showing an effective swimming performance at a speed of 0.9 $\mathrm{m} / \mathrm{sec}$.

As a result of the experiment, a decrease in the swimming speed was detected for the fish with malformation, which in terms remained behind the healthy ones when current speed increased. It was monitored that 
the deformed fish separated completely from the group at water speed of 0.8 and $0.9 \mathrm{~m} / \mathrm{sec}$. According to the results of the present study, changes in fish swimming performance depending on water velocity level showed clear evidence that water speed can be used as a practical and rapid method for identification and separation of deformed fish from the normally shaped individuals. In brief, deformed fish can be withdrawn from the culture tank with the control of water velocity, without disturbing the entire fish school and removing only those showing malformation. Since deformations in fish are considered as general skeletal deformation and there will be deformation differences between fish (lordosis angles, scoliosis or lordosis may be), statistical comparison has not been made.

\section{Discussion}

The significant effect of skeletal system deformations on the swimming speed of fish has been demonstrated earlier (Kihara et al., 2002; Başaran et al., 2009; Lijalad and Powell, 2009; Powell et al., 2009: Powel et al.2009; Davidson et al., 2011; Boglione et al., 2013).

Fish swimming speed is usually measured in body length per second (BL/sec). Özbilgin et al. (2011) reported that a mullet (Mullus barbatus) with an average body length of $16.9 \mathrm{~cm}$ had a maximum swimming speed of 3.14 $\mathrm{m}(18.58 \mathrm{BL} / \mathrm{sec})$ at $26^{\circ} \mathrm{C}$. Further Özbilgin et al. (2011) reported that a spatula fish (Diplodus annularis) with an average body length of $11,5 \mathrm{~cm}$ had a maximum swimming speed of $1,92 \mathrm{~m}(16,7 \mathrm{BL} / \mathrm{sec})$ at $20^{\circ} \mathrm{C}$.

Başaran et al. (2009) investigated the relationship between the severity of lordosis and the swimming performance of seabass juveniles between $1.44 \mathrm{~g}$ and 3.44 $\mathrm{g}$ and lengths between $5.4 \mathrm{~cm}$ and $6.5 \mathrm{~cm}$ over the course of 110-130 days experiment. They measured the spine angle of $180^{\circ}$ and reported that with the increase of lordosis severity in fish with skeletal disorders, the critical swimming speeds ( $U$ crit) declined with swimming speeds between $32.67 \mathrm{~cm} / \mathrm{sec}$ and $44.73 \mathrm{~cm} / \mathrm{sec}$, and spine angles varied between $115^{\circ}$ and $180^{\circ}$. The authors reported a significant decrease in the $U$ crit value depending on decreasing keel angle parallel to the increase in lordosis severity.

Although it is a very rare feature that the skeletal systems of fish are deformed in their natural habitats, it is normal to encounter deformations with the emergence of intensive breeding in aquaculture systems. Although these deformations do not cause any health problems in the consumption of fish as human food, and there is no negative consequence for their consumption, except their unfavorable physical appearance in marketing. Apart from the skeletal system, generally deformed structures can be found in areas such as mouth, head, gills and tail. Although malformation in cultured fish has been reduced significantly in recent years, deformation in fish hatcheries still can be seen at a rate of 7-20\% (Georgakopoulou et al., 2010). Malformation is difficult to distinguish in the early stages. Methods applied for the detection and removal of deformed fish from the culture environment are difficult and cause remarkable economic loss. Among the widely known methods of identifying deformed individuals in culture systems are (a) Observational method (parting on the light table), (b) X-ray method (>100 g), and (c) Mammography $(100 \mathrm{~g}<)$.

Although these practices are listed as useful tools in scientific reports, they may not be practical enough for the rapid identification and removal of deformed fish from the tank without disturbance on the entire fish population in the culture environment. Therefore, innovative methods are needed to overcome this problematic issue encountered in aquaculture facilities. The present study provides a practical and innovative method that might be convenient for fish farmers to separate deformed juveniles without the need to faint or kill the fish. The swimming speed characteristics of fish are among important criterion both in aquaculture facilities and fisheries activities. Hence, there is plenty of information regarding the swimming speeds of various fish species (Chatain, 1994; Chen et al., 1999; Osse and Boogard 2000), which can be very useful for the assessment of water velocity speed level for different fish species when using the flow-tank method presented in this study.

Also, several other studies have provided remarkable data for the swimming speed of seabass. Claireaux et al. (2006) reported an optimal swimming speed range between $0.3-0.6 \mathrm{~m} / \mathrm{sec}$ in European sea bass (D. labrax). Similar, in a recent study Graziano et al. (2018) reported optimum swimming speeds of 0.66 and $0.69 \mathrm{~m} / \mathrm{sec}$ for the seabass, respectively. Başaran et al. (2009) reported fish swimming speed of $44.73 \mathrm{~cm} / \mathrm{sec}$ for normal and healthy fish, while a decreased swimming speed of $32.67 \mathrm{~cm} / \mathrm{sec}$ was noted for juvenile seabass with lordosis, which are equal to 0.45 and $0.33 \mathrm{~m} / \mathrm{sec}$, respectively, and fell in a range of earlier reports.

Generally, juveniles with skeletal deformations are undesired in hatcheries which are selected and withdrawn from the culture environment by visual observation, that is time consuming and increase workload for the hatchery staff. Detecting deformed fish at an early stage and removing them from the production environment is important to reduce operating costs and specially to control feed efficiency. However, it is generally not easy to detect malformation at an early stage due to the small size of the juveniles. Therefore, in the present study small individuals of 1-2 $\mathrm{g}$ were used for this study, since it is a general approach in the Mediterranean aquaculture to transfer 1-2 $\mathrm{g}$ juveniles from the hatcheries to the offshore cage facilities in the marine environment, and the identification of malformation can be easier at this growth phase.

In fish with deformation in the skeletal structure, the growth rate will slow down, and the growth performance will decrease. In fish with deformation in the skeletal structure, the growth rate will slow down and the growth performance will decrease. In small individuals, this difference is difficult to distinguish. In cases where such fish cannot be removed from the culture environment, they continue to grow together with other healthy individuals that might lower the feed efficiency for the total biomass gain, which will result in an economic loss in terms of inputs and outputs at harvest. Additionally, fish farms do not risk their market value and the trust of consumers, hence deformed fish are generally not offered to the market. Hence removing fish with skeletal deformation at earliest growth stage seems to be the best management to lower operational costs especially feed expenses for a unit 
production gain. In conclusion, based on the findings of the present study, controlled water velocity can be used as a rapid and reliable method for the identification and mechanical removal of juveniles with skeletal deformation from the culture environment by using swimming speed as an indicator, without disturbing healthy individuals with no malformation. Further, the success of the mechanical method designed for this study provides practical and reliable method for the identification of juveniles with malformation that in terms may improve the production success and increase economic benefits of the facility with a significant contribution towards best management practice at marine fish hatcheries.

\section{Acknowledgments}

The present study was financially supported by the Scientific Research Projects Coordination Unit of Ege University under the Project No: 2018-SÜF-014, and a fast patent application has been made through Ege University EBILTEM with registration number of 2019/17658 E.Ü.

\section{References}

Afonso JM, Montero D, Robaina L, Astorga N, Izquierdo MS, Gines R. 2000. Association of a lordosis-scoliosiskyphosis deformity in gilthead sea bream. Fish Physiology and Biochemistry, 22: 159-163.

Andrades JA, Becerra J, Fernandez-Llebrez, P. 1996. Skeletal deformities in larval, juvenile and adult stages of cultured gilthead sea bream Sparus aurataL. Aquaculture, 141: 1-11.

Balebona MC, Morinigo MA, Andrades JA, Santamaria JA, Becerra J, Borrego JJ. 1993. Microbiological study of gilthead sea bream S. aurata L. elected by lordosis a skeletal deformity. Bulletin of the European Association of Fish Pathologist, 13: 33-36.

Başaran F, Özbilgin H, Özbilgin YD, Paruğ ŞŞ, Özden O. 2009. The effect of lordosis severity on juvenile sea bass (Dicentrarchus labrax L., 1758) swimming performance. Turkish Journal of Zoology, 33(4): 413-419.

Berillis P. 2015. Factors That Can Lead to The Development of Skeletal Deformities in Fishes: A Review. Journal of Fisheries Sciences.com. 9: 17-23.

Boglione C, Gavaia P, Koumoundouros G, Gisbert E, Moren M, Fontagné S, Witten PE. 2013. Skeletal anomalies in reared E uropean fish larvae and juveniles. Part 1: normal and anomalous skeletogenic processes. Reviews in Aquaculture, 5: S99-S120.

Chatain B, Dewavrin G. 1989. Influence des anomalies de développement de la vessie natatoire sur la mortalité de Dicentrarchus labrax au cours du sevrage. Aquaculture, 78: 5561.

Chatain B. 1994. Abnormal swimbladder development and lordosis in sea bass (Dicentrarchus labrax) and sea bream (Sparus aurata). Aquaculture, 119: 371-379.
Chen WM, Purser J, Blyth P. 1999, Diel feeding rhythms of greenback flounder Rhombosolea tapirina (Günther 1862): the role of light-dark cycles and food deprivation, Aquaculture Research, 30: 529-537.

Claireaux G, Couturier C, Groison AL. 2006. Effect of temperature on maximum swimming speed and cost of transport in juvenile European sea bass (Dicentrarchus labrax). J Exp Biol. 209(Pt 17): 3420-8. doi: 10.1242/jeb. 02346. PMID: 16916977.

Davidson J, Good C, Welsh C, Summerfelt ST. 2011. Abnormal swimming behavior and increased deformities in rainbow trout Oncorhynchus mykiss cultured in low exchange water recirculating aquaculture systems. Aquacultural Engineering, 45(3): 109-117.

Divanach P, Papandroulakis N, Anastasiadis P, Koumoundouros G, Kentouri M. 1997. Effects of water currents during postlarval and nursery phase on the development of skeletal deformities in sea bass (Dicentrarchus labrax L.) with functional swimbladder. Aquaculture, 156: 145-155.

Georgakopoulou E, Katharios P, Divanach P, Koumoundouros G. 2010. Effect of temperature on the development of skeletal deformities in gilthead seabream (Sparus aurata Linnaeus, 1758). Aquaculture 308: 13-19.

Graziano M, Benito R, Planas JV et al. 2018. Swimming exercise to control precocious maturation in male seabass (Dicentrarchus labrax). BMC Dev Biol 18: 10 (2018). https:// doi.org/10.1186/s12861-018-0170-8

Kihara M, Ogata S, Kawano N, Kubota I, Yamaguchi R. 2002. Lordosis induction in juvenile red sea bream, Pagrus major, by high swimming activity. Aquaculture, 212(1-4): 149-158.

Korkut AY, Kamacı HO, Çoban D, Süzer C. 2009. The First Data on The Saddleback Syndrome in Cultured Gilthead Sea Bream (Sparus aurata, L.) By MIP-MPR Method. Medwell Journals. Journal of Animal and Veterinary Advances. 8(11): 2360-2362.

Lijalad M, Powell MD. 2009. Effects of lower jaw deformity on swimming performance and recovery from exhaustive exercise in triploid and diploid Atlantic salmon Salmo salar L. Aquaculture, 290(1-2): 145-154.

O'Steen S, Bennett AF. 2003. Thermal Acclimation Effects Differ between Voluntary, Maximum, and Critical Swimming Velocities in Two Cyprinid Fishes, Physiological and Biochemical Zoology 76, no. 4 (July/August 2003): 484-496.

Osse JWM, Boogart JGM. 2000. Body size and swimming types in carplarvae; effects of being small, Netherlands Journal of Zoology, 50(2): 233-244.

Özbilgin H, Pehlivan M, Başaran F. 2011. Maximum swimming speed predictions for Mullus barbatus (Linnaeus, 1758) and Diplodus annularis (Linnaeus, 1758). Turkish Journal of Zoology, 35(1): 79-85.

Powell MD, Jones MA, Lijalad M. 2009. Effects of skeletal deformities on swimming performance and recovery from exhaustive exercise in triploid Atlantic salmon. Diseases of aquatic organisms, 85(1): 59-66

Videler JJ. 1993. Fish swimming, Chapman and Hall, New York, $254 \mathrm{p}$. 